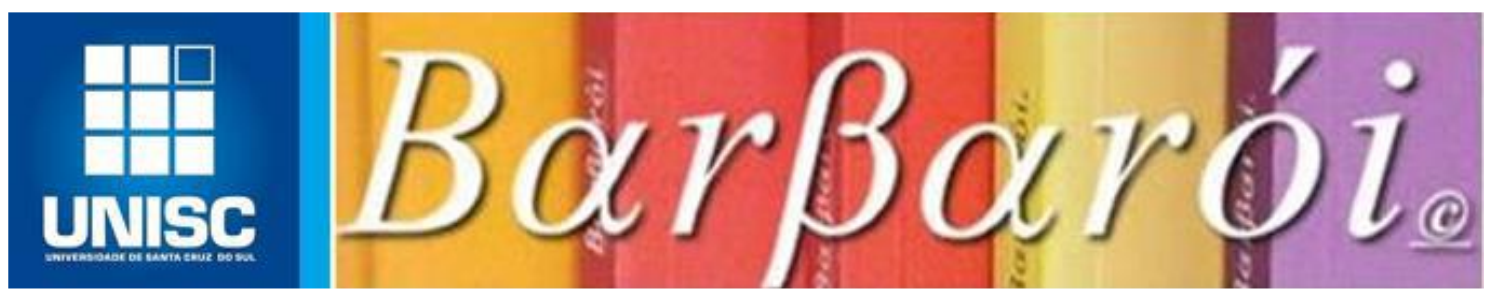

\title{
CRIMINALIZADAS E/OU VULNERÁ VEIS? A TRAJETÓRIA NO CRIME DE MULHERES APRISIONADAS POR TRÁFICO DE DROGAS
}

\author{
DOI: http://dx.doi.org/10.17058/barbaroi.v0i0.7755
}

\author{
$*$ \\ Bruna Krause de Vargas \\ Universidade do Vale do Rio dos Sinos - UNISINOS - Brasil \\ Denise Falcke \\ Universidade do Vale do Rio dos Sinos - UNISINOS - Brasil

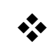

\section{Resumo}

O artigo tem por objetivo conhecer a trajetória no crime percorrida por mulheres aprisionadas por tráfico de drogas. Pretende-se ainda compreender as motivações para o ingresso das mulheres no crime, a percepçãodelas sobre o crime de tráfico de drogas e avaliar como o envolvimento com o tráfico de drogas afetou as relações amorosas, familiares e sociais dessas mulheres, além de verificar se existe o desejo de sair do crime. Participaram do estudo três apenadas da Penitenciária Estadual Feminina de Guaíba. Os resultados demonstraram que os problemas sociais e financeiros e o envolvimento familiar foram os principais motivadores para a entrada dessas mulheres no tráfico, que o tráfico era visto como uma atividade de trabalho, que o aprisionamento trouxe prejuízos para as relações, especialmente familiares, e que a saída delas do crime dependia da possibilidade de conseguir um emprego formal.

Palavras-chave: Crime, tráfico de drogas, mulheres.

\section{Introdução}

O tráfico de drogas é um crime que vem crescendo consideravelmente ao longo dos últimos anos. Conforme o último Relatório Brasileiro sobre Drogas (DUARTE; STEMPLIUK; BARROSO, 2009), que apresentou dados referentes à pesquisa realizada entre os anos de 2001 e 2009, o total de ocorrências foi de 31.368 em 2004, 35.110 em 2005, 40.941 em 2006 e 47.747 em 2007, constatando assim um aumento significativo no crime de tráfico de drogas no Brasil. Este relatório é o resultado de uma unificação de informações sobre drogas no país. Os dados utilizados foram cedidos por variadas instituições públicas e somados aos relatórios já publicados e patrocinados pela Secretaria Nacional dePolíticas sobreDrogas(DUARTE; STEMPLIUK; BARROSO, 2009). 
Segundo dados do Sistema de Informações Penitenciárias (BRASIL, 2014), entre os anos2000 e 2014, houve um aumento da população carcerária feminina no Brasil de 567,4\%. Os dados também ressaltam que 58\% dessas mulheres estão presas pelo por envolvimento com o tráfico de drogas não relacionado a grandes redes de organizações criminosas. A maior parte dessas mulheres ocupa posições coadjuvantes dentro do tráfico, sendo responsável pelo transporte das drogas e pequeno comércio, muitas são usuárias, sendo poucas as que exercem atividades de gerência dentro do tráfico (BRASIL, 2014).

Embora a maioria das mulheres ocupem posição coadjuvante no tráfico, é possível observar que com o aumento do delito, cresce também a participação das mulheres inseridas de forma ativa no tráfico de drogas. Mulheres que estão envolvidas não só nas funções mais periféricas e secundárias do crime, mas que participam também como chefes do tráfico, exercendo assim um papel de poder e alcançando cada vez mais posições de destaque dentro da rede, evolvendo-se e comandando organizações criminosas (BARCINSKI, 2012; BITENCOURT, 2012).

Este estudo sobre as mulheres e seu envolvimento com o tráfico é motivado pelos seguintes questionamentos: Quais as motivações das mulheres envolvidas com o tráfico de drogas para a entrada no crime? Quais a consequência desse envolvimento para suas relações pessoais, familiares e sociais? E quais as motivações que elas destacam como sendo necessárias para a saída dessa vida? Uma vez obtidos esses dados poderemos compreender qual o papel que elas têm assumido na rede do tráfico e quais as consequências dessa posição tanto para elas e suas famílias, como para a sociedade como um todo.

Este trabalho visa colaborar com o debate e compreender a forma como essas mulheres se envolvem no tráfico de drogas. Entende-se que, dessa forma, será possível aprimorar a compreensão acerca deste tema que tem ganhado cada vez mais relevância em nossa sociedade, mas que ainda carece de estudos científicos.

Existe uma carência de pesquisas tanto no âmbito nacional quanto internacional sobre mulheres envolvidas com crimes. Isto se deve tanto a baixa incidência de delitos cometidos, comparados ao envolvimento dos homens, quanto pela percepção de que os crimes cometidos pelas mulheres são de menor gravidade. Também existe o preconceito da sociedade e do poder público que atribuem pouco valor as manifestações de violência cometidas pelo sexo feminino, colaborando assim para que poucos estudos sejam realizados nesta área (SOUZA, 2009). A criminalidade feminina é assim pouco explorada e possuiu poucos estudos consistentes que abordem a participação de mulheres nas estatísticas envolvendo crimes e prisões (SANTOS et al., 2009).

Barbarói, Santa Cruz do Sul, n.55, p.<195-214>,jul./dez. 2019 
Além disso, faz-se necessário conhecer a trajetória dessas mulheres, pois este é um dado relevante para se formular estratégias e políticas públicas e fortalecer as já vigentes para o enfrentamento ao tráfico de drogas. Políticas que auxiliem não só as mulheres a não se envolverem no crime, mas que também auxiliem as famílias, as relações afetivas e a saúde daquelas já envolvidas no tráfico e as que se encontram encarceradas. Com o entendimento amplificado dos fatores externos e internos que levam ao ingresso no tráfico poderemos planejar e fortalecer políticas públicas que deem conta da criminalidade, diminuindo assim o número de mulheres presas por esse crime, o que pode favorecer a inserçãodelas de outra forma e com outros papeis na nossa sociedade. Nesse sentido, o estudo poderá beneficiar tanto o sistema penitenciário, quanto a sociedade como um todo.

\section{Mulheres e o tráfico de drogas}

Historicamente diversos papeis desempenhados pelas mulheres emergiram. Elas passaram de donas de casa, mães, estudantes e operárias atrabalhadoras em diferentes setores, marcando assim um empoderamento feminino dentro da sociedade. A partir de inúmeras lutas por igualdades sociais que existiram e continuam a existir as mulheresvêm cada vez mais ganhando espaço no mercado de trabalho e assumindo funções semelhantes, e até superiores, as funções masculinas (SILVA; ARANTES, 2014). Ao longo dos anos, a figura feminina também foi caracterizada por diferenciados saberes e práticas. A feminilidade, como representação social, no entanto, tem historicamente algumas características marcadas como docilidade, fragilidade, dependência, submissão e principalmente o cuidado com a família, sendo questionadas em nossa sociedade mulheres que não reproduzam este tipo de comportamento. As mulheres autoras de delitos acabam por ocupar um lugar de oposição ao esperado socialmente da figura feminina, pois são vistas pela sociedade como pertencentes a um determinado grupo social marginalizado e criminoso, que vai contra as características cultivadas ao longo dos anos pela sociedade (MARTINS, 2009).

Todas as perspectivas que vêm marcando o papel feminino ao longo da história acabam por criar na sociedade uma expectativa em relação ao papel que a mulher deve desempenhar. Sendo assim, na maioria dos casos em que existe um envolvimento feminino dentro do crime, as mulheres acabam sendo colocadas no papel de vítimas e não de perpetradoras da violência. A literatura em criminologia coloca os homens como tendo um papel central na criminalidade, levando, portanto, suas parceiras para a iniciação no crime, sendo as mulheres coadjuvantes no delito. Poucos são os estudos que identificam e colocam a mulher no papel central do crime por todo o estereótipo que carregam, sendo assim, na maior 
parte dos casos, elas ficam dentro do discurso vitimizado do sistema punitivo (BARCINSKI, 2012; JACINTO, 2011).

Esse dado é reforçado pelo Relatório da Subcomissão da Situação Carcerária (SUSEPE, 2011), que aponta que 89\% das apenadas da Penitenciária Madre Pelletier estão presas pelo crime de tráfico de drogas, a maioria mulheres que exercem papéis subalternos no crime. Tratam-se de mulheres que tentam entrar com drogas no presídio, para "ajudar" seus parceiros, ou que começam a traficar após a prisão dos mesmos com o intuito de assumir a posição que eles tinham dentro do tráfico,

Conforme Jacinto (2011), as mulheres não costumam se submeter aos perigos do crime, pois dificilmente usam da agressividade ou se envolvem em conflitos. Elas atuam de forma discreta, possuem uma maior facilidade para se movimentar dentro do tráfico sem serem percebidas pela instância policial, o que faz com que elas permaneçam mais tempo envolvidas no crime até serem presas. Acabam não sendo suspeitas em potencial o que faz com que elas assumam esse papel de auxiliar no crime. Segundo a autora, este fato também se deve ao receio que as mulheres têm de serem presas e deixarem suas famílias sem cuidado.

No discurso das mulheres envolvidas com o tráfico no Rio de Janeiro, entrevistadas por Barcinski (2012), surge um dilema entre ser uma mulher visível e reconhecida pelo tráfico ou ser uma mulher invisível e recuperada. Tal dilema mostra que o tráfico, apesar de trazer uma trajetória de perdas e violência, também é visto pelas mulheres como algo que traz benefícios, mesmo que transitórios e passageiros.

Nesta direção, existem também vantagens no envolvimento com o tráfico. Segundo Souza (2009), as mulheres envolvidas com algum ato de criminalidade ou violência costumam adentrar o espaço público, saindo assim do espaço privado de suas vidas e ganhando reconhecimento em um lugar que antes era dominado somente pelos homens.

Conforme Barcinski (2012), participar do crime dá as mulheres traficantes uma diferenciação. A cada dia as mulheres vêm conquistando ainda mais sua independência e visibilidade social e para isto elas têm usado das mais variadas formas. A partir do crime elas encontram uma maneira de se tornar visíveis, uma forma enviesada e negativa de denunciar que as coisas não vão bem com a sociedade (Barcinski, 2012). Esta acaba sendo a única maneira, ou mais viável, que estas mulheres encontram para mostrar seu sofrimento e denunciar as desigualdades sociais em que vivem, buscando assim soluções e resoluções para as suas demandas (WELTER, 2014).

Barcinski (2009a) traz um diferente olhar e refere que as mulheres envolvidas com o tráfico, principalmente aquelas envolvidas em cargos de chefia, costumam obter além de Barbarói, Santa Cruz do Sul, n.55, p.<195-214>, jul./dez. 2019 
respeito dentro da comunidade, poder sobre os demais especialmente outras mulheres e crianças. Ocupar um lugar de posse, de ostentação, ser temida pelas demais, dá a estas mulheres a possibilidade de existirem, serem respeitadas e fazerem história. Estar associada a facções criminosas, assim como andar armada, representa para estas mulheres a possibilidade de serem diferentes das demais, mesmo que o preço a pagar seja caro e traga sentimentos e consequências negativas para suas histórias de vida(BARCINSKI, 2009a).

O tráfico acabase mostrando também uma atividade econômica que possibilita a inclusão, mesmo que marginal, na sociedade capitalista. Uma opção atraente, perto de outras que são tidas como limitadas e menos imediatistas. Frente às necessidades financeiras, aliadas a falta de perspectiva de emprego, o tráficopossibilita um rápido acúmulo de capital e proporciona o reconhecimento social quesealmeja. Muitas das mulheres condenadas pelo crime de tráfico de drogas justificam o seu envolvimento com o crime pelas dificuldades financeiras, admitindo que foram motivadas pelo "dinheiro fácil" que ampliava sua possibilidade de consumo (FARIA; BARROS, 2011; MOREIRA, 2012).

Segundo Barcinski (2009a), também é necessário compreender por que mulheres que vivem em contextos similares fazem escolhas distintas de futuro. Nas entrevistas realizadas pela autora, foi verificado que as mulheres se colocavam, em alguns momentos, como protagonistas .de suas histórias e, em outros, como vítimas de uma realidade social. Elas se colocam como autoras dos crimes, mas autoras no sentindo de cometer um crime devido à realidade social que foi imposta para elas, e não por pertencerem a um perfil criminoso. Para Martins (2009), o envolvimento das mulheres com o tráfico de drogas, acontece, na maioria dos casos, pela visibilidade e pelo poder que ocasiona perante a sociedade. O envolvimento das mulheres também ocorre em função das relações familiares e afetivas que as cercam. A falta de oportunidades e o modo como se relacionam com o contexto em que elas vivem influenciam em suas escolhas (MARTINS, 2009).

O encarceramento das mulheres costuma produzir consequências nas relações familiares (SANTOS et al., 2009). Entre elas, há uma fragilização da relação dessas mulheres com seus filhos, que são afastados da convivência materna e tendo que recorrer a outros familiares ou ao Estado para dar conta de suas necessidades. Torna-se necessário se pensar em estratégias que contemplem as famílias das mulheres envolvidas com o tráfico, por elas ficarem, em muitos casos, desamparadas pelo afastamento da pessoa que era provedora e cuidadora do lar, bem como pela relação importante que se estabelece entre os vínculos familiares e a entrada e permanência no tráfico (LOPES; MELLO; ARGIMON, 2010). 
Os dados descritos reforçam a necessidade de criar e efetivar políticas públicas que contemplem, em todo o território brasileiro, as questões relativas ao tráfico e consumo de drogas, assim como à prevenção e ao tratamento dos dependentes químicos. Busca-se assim diminuir os índices de criminalidade que se intensificam por conta das drogas. A partir da percepção de que existe uma rede que envolve essas mulheres e o tráfico de drogas, uma rede de necessidades, valores, realidades que permeiam famílias e vidas. Enxergar e dar voz para estas mulheres é necessário para desmistificar a realidade em que elas vivem. Somente explorando essa vida paralela que muitas mulheres conseguem levar é que vamos conseguir que elas sejam aceitas como sujeitos com direitos que devem ser preservados e colocados em prática.

Partindo desses pressupostos, o objetivo geral deste trabalho é conhecer a trajetória no crime percorrida por mulheres aprisionadas por tráfico de drogas. Mais especificamente, pretende-se: identificar as motivações para o ingresso das mulheres no crime, conhecer a percepção delas sobre o crime de tráfico de drogas, avaliar de que forma o envolvimento com o tráfico de drogas afetou as relações amorosas, familiares e sociais dessas mulheres e verificar as motivações para sair do crime.

\section{Materiais e métodos}

Levando-se em consideração a literatura escassa sobre o tema estudado, optou-se por um estudo qualitativo exploratório. Esta modalidade de estudo é realizada quando se procura observar a complexidade de um determinado problema, levando em consideração as múltiplas interações e dinâmicas de uma determinada situação (GRESSLER, 2004).

A penitenciária foi escolhida como campo de pesquisa por ser o local onde está posto que elas estão envolvidas com o crime. Neste sentido, tornou-se o ambiente mais fácil e seguro para se abordar essa temática. Mas a escolha por este local também limitou o estudo em alguns aspectos, como a quantidade de participantes, o tempo das entrevistas, além do ambiente institucional marcado pela punição e pelo julgamento ao qual estávamos expostas, o que sem dúvida influenciou diretamente na resposta das apenadas. Além disso, a seleção das participantes foi realizada pelas agentes penitenciárias, que escolheram as "bem comportadas" e de fácil manejo, colaborativas e interessadas, o que também pode ter interferido no resultado da pesquisa. 


\subsection{Participantes}

Participaram da presente pesquisa três apenadas de uma instituição penitenciária feminina do Rio Grande do Sul, que possuem em seu histórico criminal o crime de tráfico de drogas. Das três participantes, duas assumiram envolvimento com o tráfico de drogas e uma delas afirma não ter envolvimento com o tráfico, sendo somente usuária de drogas. Ela foi mantida no estudo por atender ao critério de estar aprisionada por tráfico de drogas, sendo considerado relevante, dentro de uma perspectiva qualitativa, conhecer as idiossincrasias de cada trajetória.

A faixa etária das participantes varia entre 37 e 40 anos; a escolaridade é diversificada, ensino fundamental incompleto, médio e superior incompleto. Sobre o estado civil, uma é casada e duas solteiras todas com filhos. As participantes são do interior do estado. Das três, duas revelam associação no crime com a família, como pode-se observar na tabela 1, que apresenta dados de caracterização das participantes.

Tabela 1- Dados de caracterização das participantes

\begin{tabular}{c|c|c|c|c|c|c|c}
\hline Nome & Idade & Escolaridade & $\begin{array}{c}\text { Situação } \\
\text { Conjugal }\end{array}$ & $\begin{array}{c}\text { Número } \\
\text { de filhos }\end{array}$ & $\begin{array}{c}\text { Familiares } \\
\text { presos pelo } \\
\text { tráfico }\end{array}$ & $\begin{array}{c}\text { Há quanto } \\
\text { tempo é } \\
\text { traficante }\end{array}$ & $\begin{array}{c}\text { Usuária } \\
\text { de drogas } \\
\text { ilícitas }\end{array}$ \\
\hline P1 & 40 & $\begin{array}{c}\text { Graduação } \\
\text { Incompleta }\end{array}$ & Solteira & 1 & Não & - & $\begin{array}{c}\text { Sim há } 20 \\
\text { anos }\end{array}$ \\
P2 & 39 & $\begin{array}{c}\text { Ensino } \\
\text { Médio }\end{array}$ & Solteira & 4 & $\begin{array}{c}\text { pai, mãe e } \\
\text { irmão }\end{array}$ & 13 anos & não \\
P3 & 37 & $\begin{array}{c}\text { Fundamental } \\
\text { Incompleto }\end{array}$ & Casada & 4 & Marido & 7 anos & não \\
\hline
\end{tabular}
Fonte: elaborado pelas autoras.

\subsection{Instrumentos}

Como instrumento de pesquisa, foi utilizada uma entrevista semiestruturada com foco na trajetória das participantes dentro do tráfico de drogas. Com ela, buscamos compreender quais os elementos culturais, sociais, familiares e econômicos que influenciaram na decisão destas mulheres na entrada e as motivações para a saída do envolvimento com o tráfico de drogas, bem como suas percepções em relação às repercussões docrime de tráfico de drogas em suas relações.

Também foi aplicado um questionário sociodemográfico para coletar dados como idade, escolaridade, situação conjugal, composição familiar, entre outros. 


\subsection{Procedimentos éticos e de coleta de dados}

Inicialmente foi feito contato com a Escola de Serviço Penitenciário/RS solicitando autorização para realizar a pesquisa. A escola informou que o projeto deveria ser primeiramente aprovado pelo Comitê de Ética em Pesquisa da SUSEPE (Superintendência dos Serviços Penitenciários). Logo após ser aprovado, foi encaminhado ao Comitê de Ética em Pesquisa da Universidade - Unisinos - São Leopoldo para apreciação. Após a aprovação do projeto pelos dois comitês, a coleta de dados foi realizada a partir de contato com a Penitenciária Estadual Feminina de Guaíba, Guaíba/RS. As agentes penitenciárias indicaram presidiárias, que tinham em seu histórico criminal o tráfico de drogas. As entrevistas foram realizadas dentro do presídio devido à situação de privação de liberdade em que as participantes se encontravam. O local da entrevista foi discutido com o gestor da instituição buscando o sigilo, conforto das participantes, evitando interrupções e respeitando as regras estabelecidas pelo local.

As participantes da entrevista receberam esclarecimentos sobre sua participação na pesquisa no que se refere à garantia do anonimato na divulgação dos resultados e acesso aos resultados da pesquisa através do relatório de pesquisa ou devolução oral. As participantes da pesquisa puderam solicitar o desligamento de sua participação a qualquer momento, sem qualquer ônus ou prejuízo.

Todos os procedimentos dessa pesquisa obedeceram aos critérios da ética na pesquisa com seres humanos, Resolução ${ }^{\circ}$ 466/12 do Conselho Nacional de Saúde (2012). A pesquisa não trouxe danos às participantes, e não foi observada a necessidade de auxílio psicológico a qualquer uma das participantes. Todas assinaram o Termo de Conhecimento Livre e Esclarecido (TCLE) (BRASIL, 2002; CONSELHO NACIONAL DE SAÚDE, 2012).

Após a conclusão do estudo e análise dos dados, os mesmos serão devolvidos à instituição de coleta, a fim de que possam auxiliar na forma de compreender a vivência das mulheres envolvidas no tráfico de drogas. Nesse sentido, poderá favorecer ações específicas no atendimento dessa demanda.

\subsection{Procedimentos de análise de dados}

A pesquisa é qualitativa e a análise de dados foi realizada por meio de análise de conteúdo, conforme Bardin (2011). A partir da transcrição das respostas das participantes, foi realizada uma leitura flutuante dos dados e categorizados em unidades temáticas. Posteriormente, procedeu-se a descrição das categorias e dos resultados, sob uma perspectiva sócioconstrucionistaque tem como principal preocupação dentro de uma investigação social a Barbarói, Santa Cruz do Sul, n.55, p.<195-214>, jul./dez. 2019 
busca pelas explicações para os processos pelos quais as pessoas descrevem ou dão conta do mundo ao qual elas próprias estão inseridas (GERGEN; MCNAMEE, 1998). Os conteúdos foram compreendidos a partir da Teoria Sistêmica que percebe os sistemas como estruturas organizadas hierarquicamente que precisam ser analisadas em sua totalidade, compreendendo os aspectos macro, os níveis intermediários, e o nível mais proximal ou de microanálise (SIFUENTES et al., 2007).

\section{Resultados e discussão}

As categorias foram definidas a priori a partir dos objetivos específicos do estudo. A seguir, serão apresentadas as categorias, sua definição e as falas das participantes que foram agrupadas nas respectivas categorias que representam. Concomitantemente, os dados foram discutidos a partir da integração com a literatura sobre a temática. As categorias de análise dos dados foram:

Motivações para o ingresso no crime: Nesta categoria foram agrupadas as falas das participantessobre assuas motivaçõese formas de inserção no tráfico de drogas. Observou-se que o envolvimento da família com o crime e a falta de recursos financeiros foram questões que preponderantemente influenciaram as participantes para sua entrada no tráfico.

Duas participantes referem que possuem familiares envolvidos com o tráfico de drogas. Uma delas (P2) conta que uma parte significativa de sua família já esteve presa por questões relacionadas ao tráfico de entorpecentes (pai, mãe e irmão). A outra (P3) conta que seu ingresso no tráfico ocorreu por intermédio de seu companheiro. Segundo Silva et al., (2014), muitas apenadastêm seus crimes atrelados ao companheiro que também épresidiário, especialmente aquelas detidas pelo crime de tráfico de drogas, pois é comum que, após a prisão dos parceiros, elas assumam o "negócio". P3 é uma delas: "Fui presa por associação com meu marido. Há alguns anos, ele me traiu com outra. A gente se separou. Ele foi morar em outra cidade. Nessa época, ele acabou ficando depressivo e entrou nas drogas. Primeiro como usuário e logo depois virou traficante. Quando vi ele nessa situação de depressão acabei voltando pra ele; pra tentar ajudar, mas sabe como é, né? No tráfico só existem dois caminhos ou o cemitério ou a cadeia e aqui estamos nós. Os dois presos”.

Os problemas econômicos e sociais mostram-se também como motivos comuns para o ingresso das mulheres no tráfico de drogas. Mulheres que muitas vezes são responsáveis pelo sustento de suas famílias, que não procuram o crime diretamente, mas que acabamingressando nele como um modo alternativo pra superar os desafios que lhe são colocados diariamente Barbarói, Santa Cruz do Sul, n.55, p.<195-214>, jul./dez. 2019 
(MOURA; FROTA, 2006). Neste sentido, P2 refere como argumento para a sua inserção no tráfico a falta de dinheiro para a realização de uma cirurgia que a filha mais velha precisava. "Não tinha dinheiro para pagar a cirurgia, tive que recorrer ao tráfico como uma forma de conseguir o dinheiro de forma fácil e rápida. Além de traficante, eu também saia com homens pra receber algum dinheiro, não sou ... você sabe ... Só que eles me faziam alguns favores”.

Duas participantes referem o ingresso no sistema penitenciário por tráfico de drogas como um equívoco. P2 relata que a primeira vez que foi presa, em 2002, não tinha envolvimento com o tráfico. "estava na hora errada, no lugar errado, e acabei sendo presa". Porém, neste caso, depois desse incidente acabou entrando de fatopara o crime, pois, conforme ela, "já não tinha mais nada a perder, já estava com o nome sujo mesmo". Aponta assim, em seu discurso, dificuldades na inserção de mulheres com histórico criminal na sociedade. Bitencourt (2012) evidencia que há ausência de políticas públicas que assistam tanto as apenadas como as egressas do sistema prisional. Políticas que auxiliem no processo de ressocialização dessas mulheres, bem como a retomada no mercado de trabalho formal e na sociedade.

Por sua vez, P1 reitera seguidas vezes durante a entrevista que não é traficante, é somente usuária de drogas. "Comecei a usar cocaína, porque diziam que emagrecia. Eu era jovem e queria ser magra. Não imaginava as consequências da droga”. A fala de P1 revela duas possibilidades: a negação do tráfico ou um equívoco na sua condenação. Percebe-se que o consumo de drogas é um fator de risco ao encarceramento tendo em vista o envolvimento em um contexto de ilicitude, no qual eventualmente um usuário pode ser confundido com um traficante (RIBEIRO, 2015). Por outro lado, também é possível usuários traficarem em alguns momentos para sustentar o seu consumo e não se perceberem como traficantes.

Barcinski (2009b) cita o tráfico como meio de obtenção de recursos financeiros bem como busca de reconhecimento da comunidade, tais características aparecem na fala de P2: "No interior, as motivações para o tráfico são bem diferentes dessas que a gente vê na TV e nas favelas. No interior, não tem disputa por território. As pessoas traficam como uma forma de ganhar dinheiro. Só isso”. P2 também refere sobreos amigos e reconhecimento que o tráfico dá: "Todos te conhecem na cidade. As pessoas que circulam dentro do tráfico são bem unidas. Além é claro do dinheiro muito fácil que a droga dá. Sei que é ilegal e por isso que estou aqui, mas confesso que não me sinto pior do que os colarinhos brancos que roubam um monte no país. Não sou pior que eles, eles na verdade são iguais a mim”.

Segundo Moreira (2012), em contextos sociais desfavorecidos, o tráfico de drogas mostra-se como uma forma alternativa para a obtenção de recursos financeiros, Barbarói, Santa Cruz do Sul, n.55, p.<195-214>,jul./dez. 2019 
principalmente para a manutenção da família. Situação esta que fica clara no discurso de P2: "porque a droga dá muito dinheiro". Porém, enxerga também como ponto negativo a perda deste mesmo dinheiro "o dinheiro que vem fácil é o mesmo que some, quando tu vai presa" (P2). Esse dado corrobora a perspectiva de Telles (2009), quando refere que muitas mulheres acabam entrando nas modalidades de economia informal, que também podem ser baseadas em atividades ilegais, como uma forma de contribuir para a economia doméstica.

Percepção em relação ao crime de tráfico de drogas: Nesta categoria, foram classificadas as falas das participantes em relação à percepção delas sobre o crime de tráfico de drogas.

Duas participantes (P2 e P3) falam sobre o dinheiro fácil que a droga proporciona e demonstram em sua fala um desprendimento com o sentimento de responsabilidade por vender algo ilegal e prejudicial à saúde de outras pessoas. O tráfico, na concepção das participantes, é considerado uma atividade de trabalho como outra qualquer, ressaltando que dá muito mais dinheiro. "Dinheiro fácil e acabei ficando, sabe. Eu repassava as drogas para o vendedor. Nunca tive contato com nenhum usuário. Acho que isso faz com que o tráfico se torne um comércio como outro qualquer. Nem parecia que eu vendia droga e sim que era algo como comida, bebida, vodka. Coisas desse tipo" (P2).

Em contrapartida, P1 e P3 comentam tentativas de ajudar outras pessoas a saírem das drogas. P1 inclusive refere que fundou os narcóticos anônimos na sua cidade e que estava fazendo tratamento com uma psicóloga para não usar mais drogas. "Na semana que eu fui presa, tinha acabado de voltar de um congresso sobre dependência química. Todos na cidade sabem que sou usuária".

Observa-se ambivalência no discurso da P3. Ao mesmo em que ajudava o esposo no tráfico também tentava ajudar as pessoas a pararem de usar drogas: "Já tirei muita gente dessa vida. Tem até uma guria que tá presa aqui também que fala que fui eu que tirei ela da cocaína. Eu bem que tentei. Avisei ela, mas não adiantou. Agora ela tá aqui também. é que no tráfico o dinheiro é muito fácil. "A mesma ambivalência também aparece quando questionada sobre a sua percepção de ser traficante de drogas. Ela diz "Sinto vergonha. Prefiro ganhar 500 reais honestamente do que ganhar 5 mil por dia e perder minha liberdade. Não desejo essa vida pra ninguém. Mas também não me sinto culpada por ter sido traficante. Ninguém obriga as pessoas a usar drogas. Elas usam porque querem. Porque são um bando de vagabundos que ficam fumando crack. Porque crack é droga de pobre. É droga barata. Ninguém bota uma arma neles e manda usarem. Eles é que querem" (P3). De certa 
forma, condena-se por exercer atividade ilegal, mas refere não se sentir culpada por favorecer o acesso aos entorpecentes, indicando que as pessoas têm liberdade em usar ou não.

As mulheres e suas relações: Nesta categoria, foram selecionadas as falas das participantes com o intuito de avaliar de que forma o envolvimento com o tráfico de drogas afetou as relações amorosas, familiares e sociais dessas mulheres. Pode-se observar nesta categoria um discurso comum entre todas as participantes sobreo sofrimento pelodistanciamento de suas famílias.

O tráfico de drogas e o encarceramento trazemimplicações que envolvem todos osâmbitos da vida, sendonecessária a adaptação a um novo ambiente, agora prisional. A maternidade, suas relações familiares e as vivências amorosas são modificadas e as perspectivas de futuro procuram um novo sentido(SILVA et al., 2014). Santos et al. (2009) ressaltam que o encarceramento das mulheres produz muitas consequências nas relações familiares e sociais, em especial a perda e a fragilização do vínculo com os filhos e com pessoas mais próximas, o que pode ser observado na fala das participantes: "minha mãe tá doente e sei que é minha culpa. Por eu estar presa. Mas mesmo doente ela e meu pai me visitam todas as quartas e domingos, que é o dia das visitas e ficam uma hora, que é o tempo que ela consegue aguentar, e eles nunca deixaram de vir me visitar” (P1). Em relação ao filho, ela diz que "ele é muito ocupado e não tem tempo de me ver, mas sempre que pode ele aparece. Eu entendo, ele tem uma vida pra seguir. É claro que sinto falta dele, mas ele não precisa ficar vindo me ver”. Observa-se, novamente, uma posição bastante ambivalente das participantes. Ao mesmo tempo em que adoram as visitas e mostram-se tristes de não as receber, afirmam seguidamente que, especialmente os filhos, não precisam e não devem visitá-las. P3 refere: "não quero que eles venham. Quem cometeu o erro fui eu. Eu que tenho que pagar. Eles não precisam passar por essa humilhação. Não sei como funcionam as visitas aqui, porque nunca ninguém veio me visitar. Também nunca ouvi ninguém reclamar, mas sei de lugares onde as visitas são humilhadas. Não quero que eles passem por isso. Já basta eu estar presa. eles não precisam passar por isso. Às vezes acho que minha filha mais velha vai aparecer para me visitar, mas ela não vem. Não quero que ela venha me ver. Eu mando carta e eles respondem. Recebo no dia da visita. Eles também sempre mandam fotos. Assim me sinto mais próxima deles".

Nos relatos, é frequente a ênfase na importância da família e a falta que os familiares fazem. Guedes (2006) refere que durante o aprisionamento é comum que seja dada uma importância maior a família e que exista uma preocupação com a saúde e o bem-estar dos Barbarói, Santa Cruz do Sul, n.55, p.<195-214>, jul./dez. 2019 
familiares. O contato com a família acontece somente nos momentos de visita e nem sempre os familiares vão visitá-las por sentirem-se constrangidos com a revista prisional feminina, pela tristeza de ter um familiar preso, aspectos que acabam colaborando ainda mais para o distanciamento da família.

Com relação às mulheres entrevistadas, o impacto do aprisionamento é considerável, tendo em vista que todas são mães e que a sua prisão acaba atingindo a família como um todo. Segundo Jacinto (2011), existem pesquisas que indicam que esta é a maior preocupação das mulheres durante o aprisionamento, deixar seus filhos sem amparo. Preocupação que aparece no discurso de P3: "tenho um filho de 16 anos, e tenho muito medo que ele se envolva com o tráfico. Estou longe dele e não tenho como orientar e ensinar que no tráfico o dinheiro é muito fácil. Ele tem cabeça fraca. Cresceu vendo o pai traficar. Tem muitos amigos do tráfico. E como eu disse pra senhora antes: pra quem entra no tráfico só tem dois caminhos: o presídio ou o cemitério, e eu não quero isso pra ele, mas não tenho como ajudar estando longe. Só posso rezar pra que ele tenha cabeça boa e torcer pra que nada de ruim aconteça". Na primeira vez que P3 foi presa descobriu durante a prisão que estava grávida de um mês. Passou a gestação inteira no presídio: "meu filho me acompanhou nesse período, por isso que digo ele é meu guerreirinho que teve que aguentar comigo”. Na mesma direção, quando questionada sobre a possível relação dos filhos com o tráfico, P2 diz "eu sou mãe, né. Não quero isso pros meus filhos. Eles não. Queroeles longe disso”. Se, por um lado, o tráfico é visto como uma forma de trabalho para elas, o mesmo raciocínio não vale para os filhos.

Em relação ao esposo, P3 refere: "não quero mais saber dele. Estamos separados, e desde que fui presa não tivemos mais contato. Sei que ele não se importa. Se estivesse solto não viria me visitar. A senhora sabe que só as mulheres é que visitam os homens. Os homens não visitam as mulheres, mesmo depois que eu sair daqui não quero visitar ele”. Segundo os estudos de Silva e Arantes (2014), é comum que os companheiros abandonem suas esposas após elas serem presas, mesmo que eles façam parte da ilegalidade que as levou a prisão. As mulheres costumam ser solidárias com seus companheiros presos, fazem visitas íntimas, levam alimentos e roupas na prisão, mas os homens não tem essa mesma solidariedade para com elas quando estão presas.

Motivações para sair do crime:Nesta categoria foram classificadas as falas com o intuito de verificar as motivações dessas mulheres para não se envolverem mais com o crime de tráfico de drogas. 
Guedes (2006) afirma que muitas detentas desejam recomeçar suas vidas longe do tráfico e da violência. Reiniciando atividades como cuidar dos filhos, trabalhar e estudar como uma forma de estar perto da família e ter a proteção deles. Nesta direção, P1 fala sobre o seu envolvimento como usuária de drogas, ressaltando quenão quer mais se envolver com as drogas. "Estou presa. Alguma lição boa eu tenho que tirar daqui, que seja a vontade de viver e de me livrar do vicio, porque ele realmente me levou para o fundo do poço. Mais um pouco e eu não estaria aqui falando contigo. Como te disse, por mais incrível que pareça ser presa salvou minha vida". Refere a importância da família "Não dá pra desistir. Tem que procurar suporte na família. Só eles podem ajudar a gente a sair das drogas e é uma luta pra vida inteira. Sei que posso ficar anos sem usar e de repente me pegar tendo uma recaída. Quero voltar a trabalhar. Já conversei com meu pai. Vou assumir a chefia da fábrica dele. É uma metalúrgica. Temos vários funcionários que são ex-presidiários. Agora eles vão ter uma chefeex-presidiária" (P1). Medeiros (2010) refere que as apenadas que não têm o apoio familiar ficam mais vulneráveis à reincidência, pois com a perda desse vínculo elas perdem a proteção social primária e aumenta-se a probabilidade de retorno ao crime, justamente por não terem quem lhes ampare.

P3 revela desejo de abandonar o tráfico "Nunca mais quero passar em Guaíba. Muito menos na frente de um presídio. A roupa laranja, eu deixo pros garis usarem (risos). Eu acho importante a senhora colocar ai que essa vida dentro do tráfico não compensa. Mesmo com todo o dinheiro que vem, ser presa e ficar longe da família, não ver os filhos crescer é muito ruim, não a vale a pena. Ainda tenho uns dois anos pra puxar. Quero resgatar esse tempo perdido com a minha família, se ainda conseguir. E arrumar um emprego. Talvez em empresas de calçado. Tem bastante na minha cidade e eles costumam dar emprego pra ex presidiários".

Ainda que seja observado motivação para sair do crime (P3) e o desejo de parar de usar drogas (P1), (P2) entende o tráfico como uma alternativa financeira necessária para o caso de não conseguir emprego: "Traficar é uma necessidade. Preciso do dinheiro pra sustentar minha família. Mas também sei que é fácil perder esse dinheiro. Como é muito, a gente acaba não dando valor. Pretendo conseguir um emprego, mas sabe como é: ninguém quer dar emprego pra uma ex presidiária. As lojas da minha cidade não aceitam pessoas com esse histórico. Vou tentar, se não conseguir talvez tenha que voltar a sair com o caras e traficar". Quando questionada sobre o que seria necessário para que as pessoas saíssem do tráfico ela traz a palavra "objetivo". "Tem que ter um objetivo de vida. O tráfico dá dinheiro, mas tudo se perde quando tu é presa. Meus bens e dinheiro foram todos pra União. Perdi Barbarói, Santa Cruz do Sul, n.55, p.<195-214>, jul./dez. 2019 
tudo. Não tenho mais nada. Dinheiro que vem fácil; vai fácil." Questionada acerca de seu objetivo ela diz que é "poder criar meus filhos. Arrumar um emprego e tentar sair dessa vida, mas a senhora sabe como é, né? Nem sempre é fácil”.

Para reinserção social das detentas, torna-se necessário, conforme aponta Silva et al.(2014), a ampliação de fontes geradoras de renda. Segundo dados do Instituto Elo (COMISSÃO DE FORMAÇÃO TEÓRICA E PRÁTICA DO PRESP, 2013), cabe ao Estado o dever de propiciar a reinserção social dessas mulheres, possibilitando que elas retornem à vida em sociedade, em condições mais favoráveis do que as comparadas àquelas anteriores ao seu aprisionamento.

Bitencourt (2012) aponta em seus estudos que existe uma carência de políticas públicas relacionadas ao processo de reinserção social das ex-presidiárias que faz com que o tráfico de drogas atue na vida delas de modo similar ao mercado de trabalho convencional, relacionando assim o conceito de trabalho versus o tráfico. A prática criminosa acaba sendo,em muitos casos, a única fonte de sustento e a única possibilidade de obtenção de uma vida digna, antes e após o cárcere, e serve como alavanca para retomada de condições básicas de subsistência e reinserção social. É o que se pode observar como característica das participantes (P2 e P3) que já foram presas mais de uma vez pelo mesmo crime e tem vivido dentro do tráfico há vários anos. Segundo o mesmo autor esse processo de retomada ao crime é um processo normatizado que gera um "círculo vicioso" que inicia na ilegalidade, pela falta de oportunidades legais regimentadas e finaliza no aprisionamento. Após o cumprimento da pena, esse processo continua acontecendo devido à falta de intervenções públicas eficientes que dêem conta dessa demanda.

Nesse sentido, a partir de uma leitura sistêmica, torna-se necessário a criação e implementação de ações voltadas para mulheres egressas do sistema prisional, que levem em consideração a realidade que cerca estas mulheres. É um grande desafio, para as políticas públicas como um todo, construir ações voltadas para as mulheres marcadas pelo tráfico, pelo cárcere e pela privação de liberdade, assim como contemplar seus núcleos familiares e sociais, diminuindo a perpetuação da cultura do tráfico e prevenindo a reinserção no crime (COMISSÃO DE FORMAÇÃO TEÓRICA E PRÁTICA DO PRESP, 2013).

\section{Considerações Finais: Afinal criminalizadas e/ou vulneráveis?}

Diante do exposto na literatura e na pesquisa, entende-se que o papel da mulher não pode ser reduzido a somente uma das duas afirmações "criminalizadas ou vulneráveis". As participantes desta pesquisa mostram-se mães, esposas, cuidadoras do lar, trabalhadoras, Barbarói, Santa Cruz do Sul, n.55, p.<195-214>, jul./dez. 2019 
criminalizadas no ponto de vista jurídico, e vulneráveispor serem vítimas de uma sociedade capitalista e excludente que apresenta inúmeras desigualdades sociais e de gênero. Entende-se que as mulheres não podem ser resumidas a somente um papel. Mulheres que são autoras de suas histórias e de suas escolhas, mas que precisam de subsídios para enxergar e pensar em novas possibilidades de vida. Embora fique claro neste estudo que estas participantes tiveram a influência masculina e familiar para a sua entrada no tráfico, bem como as dificuldades financeiras, não podemos deixar de lado o protagonismo delas frente as suas escolhas. Sistemicamente, compreende-se que os fatores sociais e culturais contribuem para a entrada e permanência destas mulheres no crime e que muitos são os aspectos que permeiam essas relações e que corroboram para que elas se mantenham. Torna-se desta forma importante ressaltar as especificidades dos crimes cometidos por mulheres, com o intuito de dar maior visibilidade a elas, e para um melhor entendimento sobre esse complexo estudo que vai muito além do questionamento realizado de criminalizadas e/ou vulneráveis.

Fica clara a necessidade de novos estudos sobre a temática das mulheres envolvidas com o tráfico, tendo em vista não só o aumento significativo deste crime nos últimos anos como também toda a questão social que está envolvida no comércio ilegal de drogas e que convoca todos a se envolver com esse debate. A necessidade de novos estudos inclusive fica registrada na fala de uma das participantes "É muito importante que tu tenha vindo aqui, olhar pra nós, ninguém fala sobre as mulheres presas" (P3). Já P1 refere o desejo de ler o trabalho depois de finalizado, demonstrando que a temática as afetou de alguma forma, deu espaço pra que elas refletissem sobre sua própria vida e propiciou que elas fossem ouvidas. As entrevistas foram intensas, permeadas por muito choro e emoção por parte das participantes, ao revelarem aspectos tão peculiares de suas vidas.

Esta talvez tenha sido a maior contribuição deste trabalho: poder ouvir essas mulheres, mesmo que em número pequeno e com diversas limitações na pesquisa, mas mulheres que se mostram dispostas a denunciar os problemas sociais e culturais aos quais estãoexpostas. Cabe a todos nós a responsabilidade de problematizar tais questões, pois na medida em que o crime e o uso de substâncias crescem também somos afetados pelo aumento da violência. Sendo assim torna-se necessário dar espaço para novas possibilidades de vida, para os novos papéis e formas de existir dessas mulheres.

\section{CRIMINALIZADA Y/O VULNERABLE? UNA TRAYECTORIA EN LOS CRÍMENES DE PRISIONERAS ARRESTADAS POR NARCOTRÁFICO}

\section{Resumen}

Barbarói, Santa Cruz do Sul, n.55, p.<195-214>, jul./dez. 2019 
El artículo tiene como objetivo comprender la trayectoria de los delitos cubiertos por las mujeres detenidas por tráfico de drogas. Otro de los objetivos es entender las motivaciones para la entrada de las mujeres en el crimen, su percepción sobre el crimen tráfico de drogas y evaluar cómo la participación en el tráfico de drogas afecta a las relaciones sentimentales, familiares y sociales de estas mujeres, así como de verificación hay un deseo de dejar el crimen. El estudio incluyó tres apenadas Penitenciario del Estado de Mujeres Guaíba. Los resultados demostraron que la participación de los problemas sociales y económicos y familiares fueron las principales razones para el ingreso de estas mujeres la trata, el tráfico se vio como una actividad de trabajo, que el encarcelamiento trajo daño a las relaciones, especialmente los miembros de la familia, y a cabo el delito dependía de la posibilidad de conseguir un trabajo formal.

Palabras clave: delincuencia, el tráfico de drogas, mujeres.

\title{
CRIMINALIZED AND / OR VULNERABLE? THE CRIME TRAJECTORY OF WOMEN ARRESTED FOR DRUG TRAFFICKING
}

\begin{abstract}
The article has the objective of know the crime trajectory course of women imprisoned for drug traffic. It is intended to comprehend the motivations for the entering of the women on crime, the perception of the women about the crime on drug traffic and evaluate how the involvement with the drug traffic affected the romantic, familiar and social relationships of these women, also to verify if exists a desire to get out of crime. Three imprisoned women of the Penitênciária Estadual de Guaíba (Guaíba's States Penitentiary) participated in this study. The results show that financial and social problems along with the family involvement, were the principal motivators to the entering of these women in the drug traffic, that the traffic was seen as a work activity, that the imprisonment brought losses for the relationships, especially family, and that the exit of crime was dependent of the possibility of get a formal job.
\end{abstract}

Key-words: Crime, drug traffic, womens.

\section{REFERÊNCIAS}

BARCINSKI, Mariana. Mulheres no tráfico de drogas: a criminalidade como estratégia de saída da invisibilidade social feminina.Contextos Clínicos, São Leopoldo, v. 5, n. 1, p. 52-61, 2012. Disponível em: $<$ http://pepsic.bvsalud.org/scielo.php?script=sci_arttext\&pid=S198334822012000100007\&lng=pt\&nrm=iso>. Acesso em: 06 Jan. 2019. DOI: 10.4013/ctc.2012.51.06.

BARCINSKI, Mariana. Centralidade de gênero no processo de construção da identidade de mulheres envolvidas na rede do tráfico de drogas.Ciência \& Saúde Coletiva, Rio de Janeiro, v. 14, n. 5, p. 1843-1853, 2009a. Disponível em<http://www.scielo.br/scielo.php?script=sci_arttext\&pid=S141381232009000500026\&lng=en\&nrm=iso>. Acesso em: 08 Jan. 2019. DOI: 10.1590/S141381232009000500026 .

BARCINSKI, Mariana. Protagonismo e vitimização na trajetória de mulheres envolvidas na rede do tráfico de drogas no Rio de Janeiro.Ciência \& Saúde coletiva, Rio de Janeiro, v. 14, n. 2, p. 577-586, Apr. 2009b. Disponível em:

<http://www.scielo.br/scielo.php?script=sci_arttext\&pid=S1413-

Barbarói, Santa Cruz do Sul, n.55, p.<195-214>,jul./dez. 2019 
81232009000200026\&lng=en\&nrm=iso>. Acesso em: 24 Mar. 2019. DOI: 10.1590/S141381232009000200026 .

BARDIN, Laurence. Análise de conteúdo. Lisboa: Edições 70, 2011.

BITENCOURT, Álvaro Hummes. Mulheres \& sistema prisional: o sentido do trabalho para quem viveu e vive sob a égide do cárcere.Dissertação de mestrado não publicada, Pontifica Universidade Católica do Rio Grande do Sul, Porto Alegre, 2012. Disponível em:

http://repositorio.pucrs.br/dspace/bitstream/10923/1953/1/000444370-Texto\%2bParcial-0.pdf Acesso em: 22 Fev. 2019.

BRASIL. Novo Código Civil: lei no10. 406. Brasília, DF, 10 de janeiro de 2002. BRASIL. Ministério de Justiça, Departamento Penitenciária Nacional. Infopen Estatistica, 2014.

COMISSÃO DE FORMAÇÃO TEÓRICA E PRÁTICA DO PRESP. O egresso do sistema prisional: do estigma à inclusão social. Instituto Elo, 2013.

CONSELHO NACIONAL DE SAÚDE. Resolução n⿳4066/12. Diretrizes e normas regulamentadoras de pesquisas envolvendo seres humanos. Brasília, DF, 2012.

DUARTE, Paulina Carmo Arruda Vieira; STEMPLIUK, Vladimir Andrade; BARROSO, Lúcia Pereira. Relatório brasileiro sobre drogas.Brasília: Secretaria Nacional Sobre Drogas/SENAD, 2009.

FARIA, Ana Amélia Cypreste; BARROS, Vanessa de Andrade. Tráfico de drogas: uma opção entre escolhas escassas.Psicologia \&Sociedade, Florianópolis, v. 23, n. 3, p. 536-544, 2011. Disponível em: $<$ http://www.scielo.br/scielo.php?script=sci_arttext\&pid=S010271822011000300011\&lng=en\&nrm=iso>. Acesso em: 24 Fev. 2019. DOI: 10.1590/S010271822011000300011.

GERGEN, Kenneth.J.; MCNAMEE, Sheila. A terapia como construção social. Porto Alegre: Artes Médicas, 1998.

GUEDES, Marcela Ataide. Intervenções psicossociais no sistema carcerário feminino.Psicologia:Ciência e profissão, Brasília, v. 26, n. 4, p. 558-569, 2006. Disponível em:<http://pepsic.bvsalud.org/scielo.php?script=sci_arttext\&pid=S141498932006000400004\&lng=pt\&nrm=iso>. Acesso em 24 Fev. 2019.

GRESSLER, Lory Alice. Introdução à pesquisa. Edições Loyola, 2004.

JACINTO, Gabriela. Mulheres presas por tráfico de drogas e a ética do cuidado.Revista Sociais e Humanas, v. 24, n. 2, p. 36-51, 2011. Disponível em: <https://periodicos.ufsm.br/sociaisehumanas/article/view/2848> Acesso em 24 Fev. 2018.

LOPES, Regina Maria Fernandes; MELLO, Daniela Canazaro; ARGIMON, Irani L.. Mulheres encarceradas e fatores associados a drogas e crimes. Ciências \& Cogniçãa, Rio de Janeiro, v. 15,n. 2,p. 121-131,2010. Disponível em $<$ http://pepsic.bvsalud.org/scielo.php?script=sci_arttext\&pid=S180658212010000200011\&lng=pt\&nrm=iso>. Acesso em: 24 Fev.2019. 
MARTINS, Simone. A mulher junto às criminologias: de degenerada à vítima, sempre sob controle sociopenal.Fractal, Rio de Janeiro,v. 21,n. 1,p. 111-123, 2009. Disponível em: $<$ http://www.scielo.br/scielo.php?script=sci_arttext\&pid=S1984-

2922009000100009\&lng=en\&nrm=iso>. Acesso em: 24 Nov. 2019. DOI: 10.1590/S198402922009000100009 .

MEDEIROS, Luciana Lessa. Mulheres e cárcere-reflexões em torno das redes de proteção social.Anais do X Encontro Nacional de História Oral Testemunhos: História e Política. Universidade Federal de Pernambuco, Centro de Filosofia e Ciências Humanas, 2010. Disponível em: http://www.sul2013.historiaoral.org.br/resources/anais/2/1269096793_ARQUIVO_Trabalhoc ompletomulheresecarcere.pdf Acesso em: 22 Mar. 2019.

MOREIRA, Vanessa dos Santos. Impactos do envolvimento de mulheres presidiárias com o fenômeno das drogas. Dissertação de Mestrado em Enfermagem -Escola de Enfermagem da Universidade Federal da Bahia, Salvador, 2013. Disponível em:

<https://repositorio.ufba.br/ri/handle/ri/11765> Acesso em: 24 Fev. 2019.

MOURA, Maria Jurema de; FROTA, Maria Helena de Paula. Dilacerando os fios, tricotando às avessas, construindo a trama: mulher, tráfico de drogas e prisão. $\mathrm{O}$ público e o privado,

Revista do Programa de Pós-Graduação em Sociologia da Universidade Estadual do Ceará, n. 8, 2006. Disponível em

<http://www.seer.uece.br/?journal=opublicoeoprivado\&page=article\&op=view\&path $\% 5 \mathrm{~B} \% 5$ $\mathrm{D}=168>$ Acesso em: 24 Fev. 2019.

RIBEIRO, Daniel Miranda. Os efeitos nocivos da política antidrogas na dignidade e saúde dos usuários de drogas ilícitas.Monografia (Bacharelado em Direito) - Universidade de Brasília, Brasília, 2015. Disponível em:<http://bdm.unb.br/handle/10483/10822 $\geq$ Acesso em: 24 Mar. 2019.

SANTOS, Maricy Beda Siqueira; NÉRI, Heloneida Ferrari; OLIVEIRA, Maria Fernanda Leite; QUITETE, Byanka; SABROZA, Adriane. Do outro lado dos muros: a criminalidade feminina. Mnemosine, v. 5, n. 2, 2009. Disponível em: <https://www.epublicacoes.uerj.br/index.php/mnemosine/article/view/41439 $\geq$ Acesso em: 05 Mar. 2019.

SIFUENTES, Thirza Reis; DESSEN, Maria Auxiliadora; OLIVEIRA, Maria Claudia Santos Lopes. Desenvolvimento humano: Desafios para a compreensão das trajetórias probabilísticas.Psicologia: Teoria e Pesquisa, v. 23, n. 4, p. 379-386, 2007.

SILVA, Denize da; ARANTES, Almir. O processo de ressocialização das mulheres privadas de liberdade no anexo penitenciário de Sinop-MT.Revista Eventos Pedagógicos, v. 5, n. 2, p. 74-82, 2014. Disponível em:

<http://sinop.unemat.br/projetos/revista/index.php/eventos/article/viewFile/1481/1159> Acesso em: 02 Mar. 2019.

SILVA, Eloina Ariana Ribeiro Damasceno; ARAUJO, Maria Iracema de Souza; DE CASTRO, Thalita Silva; DA SILVA, Yramaiane Tomaz; MOREIRA, Jùnnia Maria. Realidade prisional feminina: problemas enfrentados pelas detentas e possibilidades de reinserção social. Extramuros-Revista de Extensão da Univasf, v. 2, n. 1, 2014. Disponível em: 
$<$ https://www.researchgate.net/publication/321253122_Realidade_prisional_feminina_proble mas_enfrentados_pelas_detentas_e_possibilidades_de_reinsercao_social> Acesso em 24 Fev. 2019.

SOUZA, Kátia Ovídia José de. A pouca visibilidade da mulher brasileira no tráfico de drogas.Psicologia em Estudo, Maringá,v. 14,n. 4,p. 649-657, 2009. Disponível em: <http://www.scielo.br/scielo.php?script=sci_arttext\&pid=S1413-

$73722009000400005 \& l n g=e n \& n r m=i s o>$. Acesso em 24 Fev. 2019. DOI: 10.1590/S141373722009000400005 .

SUSEPE, Superintendência dos Serviços Penitenciários, Subcomissão da Situação Carcerária. Assembléia Legislativa do Estado do Rio Grande do Sul.Relatório final, 2011.

TELLES, Vera da Silva. Ilegalismos urbanos e a cidade.Novos estudos - CEBRAP, São Paulo, n. 84, p. 153-173, 2009. Disponível

em: $<$ http://www.scielo.br/scielo.php?script=sci_arttext\&pid=S0101-

33002009000200009\&lng=en\&nrm=iso>. Acesso em: 22 Mar. 2019. DOI:10.1590/S010133002009000200009.

WELTER, Maria Estela. A mulher no sistema prisional brasileiro.Trabalho de conclusão de curso não publicado, Universidade Regional do Noroeste do Estado do Rio Grande Sul, Santa Rosa, 2014. Disponível em:<http://bibliodigital.unijui.edu.br:8080/xmlui/handle/123456789/2102> Acesso em 02 Mar. 2019.

Data de recebimento: $24 / 06 / 2016$

Data de aceite: 13/11/2019

\section{Sobre as autoras:}

Bruna Krause de Vargas é Psicóloga, Pós-graduanda da Residência Integrada

Multiprofissional em Saúde da Criança - violências e vulnerabilidades da Universidade Federal do Rio Grande do Sul. Endereço Eletrônico: bruna_vargas@yahoo.com.br

Denise Falcke é Psicóloga, Especialista em Terapia de Casal e Família pelo Instituto de Terapias Integradas (ITI), Mestre em Psicologia Clínica (1998) e Doutora em Psicologia pela Pontifícia Universidade Católica do Rio Grande do Sul (2003). Atualmente, é professora adjunta do Programa de Pós-Graduação em Psicologia da Universidade do Vale do Rio dos Sinos (Unisinos). É bolsista de produtividade do CNPq e coordena o Núcleo de Estudos de Família e Violência (NEFAV). Endereço Eletrônico: dfalcke@ unisinos.br 